\title{
Review Article \\ Insulin and the Lung: Connecting Asthma and Metabolic Syndrome
}

\author{
Suchita Singh, ${ }^{1}$ Y. S. Prakash, ${ }^{2,3}$ Allan Linneberg, ${ }^{4}$ and Anurag Agrawal ${ }^{1}$ \\ ${ }^{1}$ Center of Excellence for Translational Research in Asthma \& Lung Disease, CSIR-Institute of Genomics and Integrative Biology, \\ New Delhi 110007, India \\ ${ }^{2}$ Department of Anesthesiology, Mayo Clinic, Rochester, MN 55905, USA \\ ${ }^{3}$ Department of Physiology \& Biomedical Engineering, Mayo Clinic, Rochester, MN 55905, USA \\ ${ }^{4}$ Research Center for Prevention and Health, Glostrup University Hospital, Glostrup 2600, Denmark
}

Correspondence should be addressed to Anurag Agrawal; a.agrawal@igib.in

Received 23 March 2013; Revised 8 August 2013; Accepted 21 August 2013

Academic Editor: Balaram Ghosh

Copyright (C) 2013 Suchita Singh et al. This is an open access article distributed under the Creative Commons Attribution License, which permits unrestricted use, distribution, and reproduction in any medium, provided the original work is properly cited.

Obesity, metabolic syndrome, and asthma are all rapidly increasing globally. Substantial emerging evidence suggests that these three conditions are epidemiologically and mechanistically linked. Since the link between obesity and asthma appears to extend beyond mechanical pulmonary disadvantage, molecular understanding is necessary. Insulin resistance is a strong, independent risk factor for asthma development, but it is unknown whether a direct effect of insulin on the lung is involved. This review summarizes current knowledge regarding the effect of insulin on cellular components of the lung and highlights the molecular consequences of insulin-related metabolic signaling cascades that could adversely affect lung structure and function. Examples include airway smooth muscle proliferation and contractility and regulatory signaling networks that are associated with asthma. These aspects of insulin signaling provide mechanistic insight into the clinical evidence for the links between obesity, metabolic syndrome, and airway diseases, setting the stage for novel therapeutic avenues targeting these conditions.

\section{Introduction}

It is now well recognized that obesity and asthma are epidemiologically linked [1-4]. Such a relationship is also seen between asthma and other markers of the metabolic syndrome such as insulin resistance and hypertension that cannot be accounted for by increased body mass alone [47]. While both obesity and asthma are individually associated with an increased state of inflammation [8], interestingly, in obese asthmatics, there is a dissociation between cellular inflammation and severity of symptoms, especially in women $[9,10]$. This discordance would suggest that while obesityrelated systemic inflammation can certainly be one mechanism for increased asthma risk, there is a need to examine mechanisms independent of cellular inflammation that may play a role in asthma in the context of conditions such as obesity and metabolic syndrome.

A number of cellular signaling and metabolism mechanisms could contribute to increased asthma risk in patients with obesity and/or metabolic syndrome. Considering the fact that altered glucose metabolism occurs in both cases, and hyperinsulinemia with reduced insulin sensitivity is involved, an obvious potential factor affecting the lung is insulin itself, particularly a direct effect on structural cells as well as immune cells in the airway. In a large Danish cohort, it was observed that insulin resistance (IR) was more strongly related to asthma risk than any of the anthropometric parameters [11]. While this study did not specifically examine serum insulin, independent of blood glucose or diabetes, it is recognized that insulin resistance (IR) and consequent hyperinsulinemia are central molecular pathologies in the genesis of the metabolic syndrome [12,13]. Other markers of metabolic syndrome such as $\mathrm{C}$-reactive protein and correlates such as hyperglycemia, diabetes, or hypertension have all been associated with reduced lung function, asthma [14], or even COPD [15], in large clinical studies. Yet the direct impact of hyperinsulinemia and IR on lung function is poorly understood. If insulin excess can directly alter lung cellular 
physiology, this would represent a fundamental common molecular link between asthma and the cardiometabolic syndrome [16].

This review focuses on the current stage of knowledge regarding the direct effects of insulin in lung cells in the context of airway remodeling and hyperresponsiveness. Here, it is important to emphasize that in fact there is a significant knowledge gap regarding insulin effects in the airway, and we therefore draw upon what is known in other cell types to generate hypotheses that could drive future research. Certainly, our focus on insulin does not rule out several other potential mechanisms such as dysfunctional arginine metabolism and uncoupling of nitric-oxide synthase (NOS) by increased asymmetric dimethyl arginine (ADMA) [17], effects of adipokines, and direct mechanical effects of thoracoabdominal obesity on lung mechanics. These important topics are reviewed in detail elsewhere in this issue.

\section{Insulin and IR}

Insulin is one of the central homeostatic hormones with global effects that extend beyond glucose and lipid metabolism. As a pleiotropic hormone [18], insulin effects range from the well-known hypoglycemia to regulation of cell growth and differentiation $[19,20]$. Insulin regulates a number of key metabolic biological processes such as stimulation of glucose uptake, lipid synthesis, oxidation, storage of fat, and cell proliferation [21-23]. Insulin-mediated signaling varies significantly between cells and tissues necessitating an understanding of its actions in the context of the lung and in specific cell types within the lung. Insulin resistance (IR), that is, reduced responsiveness to insulin in liver, muscle, and adipose tissue, is closely associated with various metabolic diseases such as obesity, metabolic syndrome, nonalcoholic fatty liver disease [24], and type 2 diabetes mellitus [25]. Since IR in key metabolic tissues is associated initially with compensatory hyperinsulinemia, insulin-related effects that retain sensitivity in other tissues are expected to be increased, even in the face of metabolic IR. This is a partial reflection of distinct physiological processes in multiple organs [26] and is important because IR is also associated with other putatively nonmetabolic diseases such as asthma [4, 27] and some cancers [28-32]. While relative deficiency of insulin and hyperglycemia are well studied in diabetes, the harmful effects of insulin excess are poorly recognized except where they result in hypoglycemia. Importantly, given the cell- and tissue-specific heterogeneity in insulin signaling and the potential confounding role of disease states per se, effects on other tissues may not be easily extensible to the lung. Nonetheless, considerable insight into potential mechanisms by which insulin influences lung cellular components relevant to asthma may be gleaned from such prior data.

\section{Insulin and the Lung}

Expression of insulin receptors in the lung has been verified [33]; however, their role has only been partially characterized using crude membrane of normal lung as well as plasma membrane fractions of lung tissue. Importantly, interaction of these receptors with insulin appears to be time and temperature dependent, and furthermore rapid, saturable, and highly reversible $[34,35]$. The relevance of these findings is that insulin has the potential to dynamically influence lung structure and function at various life stages and thus modulating asthma predisposition.

Insulin receptors are important during lung development with lung epithelial cells abundantly expressing insulin receptors during the pseudoglandular stage with receptor levels decreasing during later stages of development [36]. Assuming that maternal insulin is the agonist, these data fit well with prior evidence that maternal diabetes has substantial growth effects on fetal lungs. Miakotina et al. and others have shown that high insulin levels delay lung development in fetuses of diabetic mothers by inhibiting surfactant protein A (SP-A) [37]. Inhibition of SP-A and SP-B genes' expression leads to increased incidence of respiratory distress syndrome (RDS) in infants of diabetic mothers [38]. In a large Canadian study, asthmatic children were more likely to be of diabetic mothers than children without asthma [39]. What is less clear, but is likely, is whether these diabetic mothers had hyperinsulinemia [40]. Furthermore, alternative mechanisms may be at play, including hyperglycemia, and altered cytokine/adipokine milieu.

While these clinical associations are clear, there is limited experimental evidence supporting a direct role for insulin per se in lung development. In cultured lung epithelial cells, insulin reduces VEGF expression and transcriptional activity of HIF-2 on VEGF promoter in an mTOR-dependent manner. The importance of the Akt-mTOR pathway in lung epithelium relates to the pathogenesis of infant RDS [41] which predisposes towards asthma later in life. Animal models of hyperinsulinemia are more complex with at least one report of accelerated fetal lung maturation in pregnant rabbits by a two-day intravenous (IV) infusion of insulin, but with significant hypoglycemia [42]. Accordingly, it is difficult to conclude whether insulin is promaturation when it comes to lung development, and here it is important to consider whether the timing of high versus low level of insulin receptor expression and activation is a confounding factor.

Other than effects of insulin on developing lungs, recent efforts towards developing inhaled insulin formulations for diabetes management have provided interesting insights into direct effects of insulin on the mature lung. Since the pulmonary epithelium and the surfactant that lines the alveoli $(0.1-0.2 \mu \mathrm{m}$ thick) constitute physical barriers to pulmonary absorption, local deposition and action of insulin are to be expected. Locally high concentrations of protease inhibitors and acidic formulations seem to protect the insulin peptide from membrane-associated cells and intracellular proteases [43-45] resulting in much of the inhaled insulin being absorbed systemically in the alveolar region. However, despite good systemic delivery, there also appears to be substantial local effect of inhaled insulin. For example, inhaled insulin in diabetic patients is associated with a decrease in forced expiratory volume in 1 second (FEV1) [46, 47], but the mechanisms are not clear. Certainly, insulin can shift $\mathrm{T}$ cells 
towards a Th2-type response, known to be a key event in the pathogenesis of asthma [48]. It has also been observed that insulin, via activation of PI3K pathway, promotes mast cell survival and degranulation, which facilitate bronchoconstriction [49]. Nonspecific proinflammatory effects via activation of pulmonary macrophages are also possible, and in some studies it has been shown that inhaled insulin may deposit at air-tissue interfaces with characteristics of amyloid aggregates [50]. The relevance of these findings may be in that inhaled formulations of insulin that were once promising, approved strategies for treatment of diabetes mellitus in US and Europe $[51,52]$ have been withdrawn due to persistent reports of respiratory problems, including cough. On the other hand, it appears that insulin also has anti-inflammatory effect in the context of severe Thl-type inflammation. Insulin has been found to reduce levels of inflammatory cytokines, attenuate acute lung injury and systemic inflammatory response, and promote survival in rodents exposed to LPS [53].

Collectively, these limited data again suggest a dichotomous role for insulin where increased levels of insulin in the mature (adult) lung have found to be detrimental on the one hand but protective on the other. What is important to determine is whether systemic hyperinsulinemia as occurring in metabolic syndrome leads to pathophysiological changes leading to asthma, or is protective, and the mechanisms by which insulin acts on the airway.

\section{Insulin and Airway Smooth Muscle}

While asthma is usually defined as an inflammatory disease, a cardinal feature is airway hyperresponsiveness (AHR): excessive narrowing of airways in response to normal constrictive stimuli [54]. AHR is associated with increase in airway smooth muscle (ASM) mass, dysfunction of bronchial epithelium, and alterations in extracellular matrix (ECM) within the airway wall. Increased ASM mass is considered to play a key role in the development of AHR [55] and activate epithelial mesenchymal trophic unit (EMTU) that leads to airway remodeling.

As a growth factor, the contribution of insulin to increased ASM mass and/or contractility in the context of asthma is obviously important.

Noveral and colleagues first showed that functional insulin-like growth factor-1 (IGF-1) receptors are present on rabbit ASM and that their stimulation is sufficient to induce ASM proliferation [56, 57]. These studies have been replicated in other animal model systems, and the pathway was determined to be activation of the MAP kinase system [58]. It is well known that insulin and IGF-1 can crossactivate each other's receptors (insulin receptor (InsR) and IGF1R) and that there is also significant crosstalk downstream to these receptors via the insulin receptor substrate proteins (IRS; Figure 1). It has been subsequently shown that high levels of insulin promote ASM contraction [59] and enhance contractile responses to methacholine and $\mathrm{KCl}[60,61]$. These effects have been reported to occur via Rho kinase- and PI3 kinase-dependent signaling pathways $[62,63]$. Other reports suggest that insulin increases ECM proteins such as laminin (a2, b1, and g1 chain expression) [64] which are important

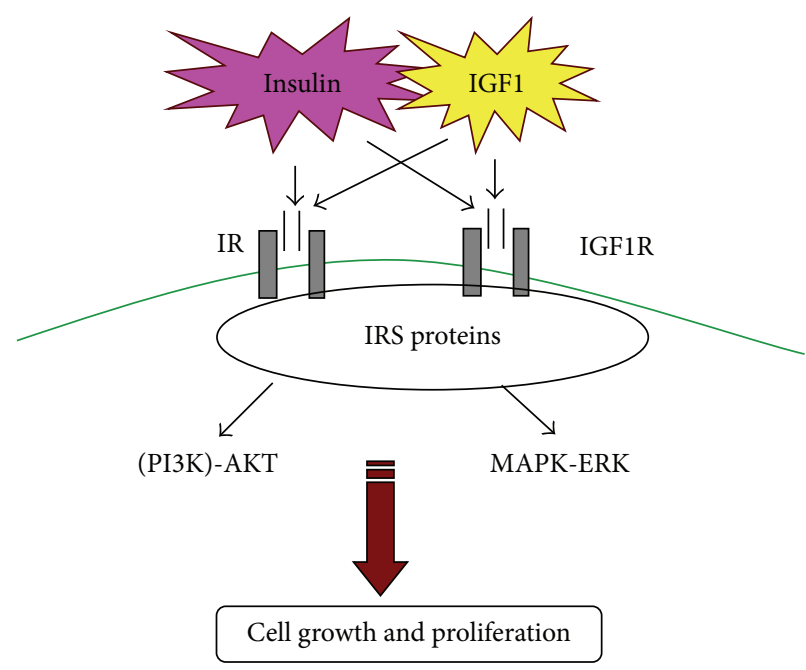

FIGURE 1: Insulin and IGF-1 can crossactivate each other's receptors, that is, insulin-IGF1R, IGF1-IR, which can lead to insulin-mediated cell growth and proliferation.

in lung growth and differentiation of naïve mesenchymal cells, leading to hypercontractile and hypoproliferative ASM $[65,66]$. Furthermore, limited studies suggest that aerosol administration of insulin leads to ASM contraction but indirectly via production of procontractile prostaglandins that involve Rho kinase [67]. Overall, the data so far suggests that, if anything, insulin effects on ASM are likely to result in increased airway contractility, cell proliferation, and fibrosis, all of which should lead to a thicker, stiffer, and hypercontractile airway reflective of an asthma phenotype. However, it is also important to recognize that much of the work has been in vitro, with high levels of insulin, typically applied for relatively short periods. Whether prolonged hyperinsulinemia and/or activation of insulin receptors leads to different cellular effects in the airway, and whether such effects are reversible (in the context of therapy) remain to be determined.

\section{Insulin and PI3/Akt Signaling}

PI3K/Akt signaling has a central role in the conserved downstream pathway of insulin signaling $[68,69]$ and is an important regulator of diverse array of cellular events, including cell growth and cell survival in a number of cell types [70]. Several studies have validated the functional significance of the PI3K pathway in glucose homeostasis and shown that PI3K inhibition leads to insulin resistance [71, 72].

It has been also shown that insulin is a potent activator of PI3K in human bronchial epithelial cells and inhibits TLR3 mediated apoptosis [73]. It has been also shown that insulin, via activation of PI3K pathway, promotes mast cell survival and degranulation, which may leads to bronchoconstriction [49].

This pathway is also thought to be important at least in prenatal lung development in the context of maternal diabetes 


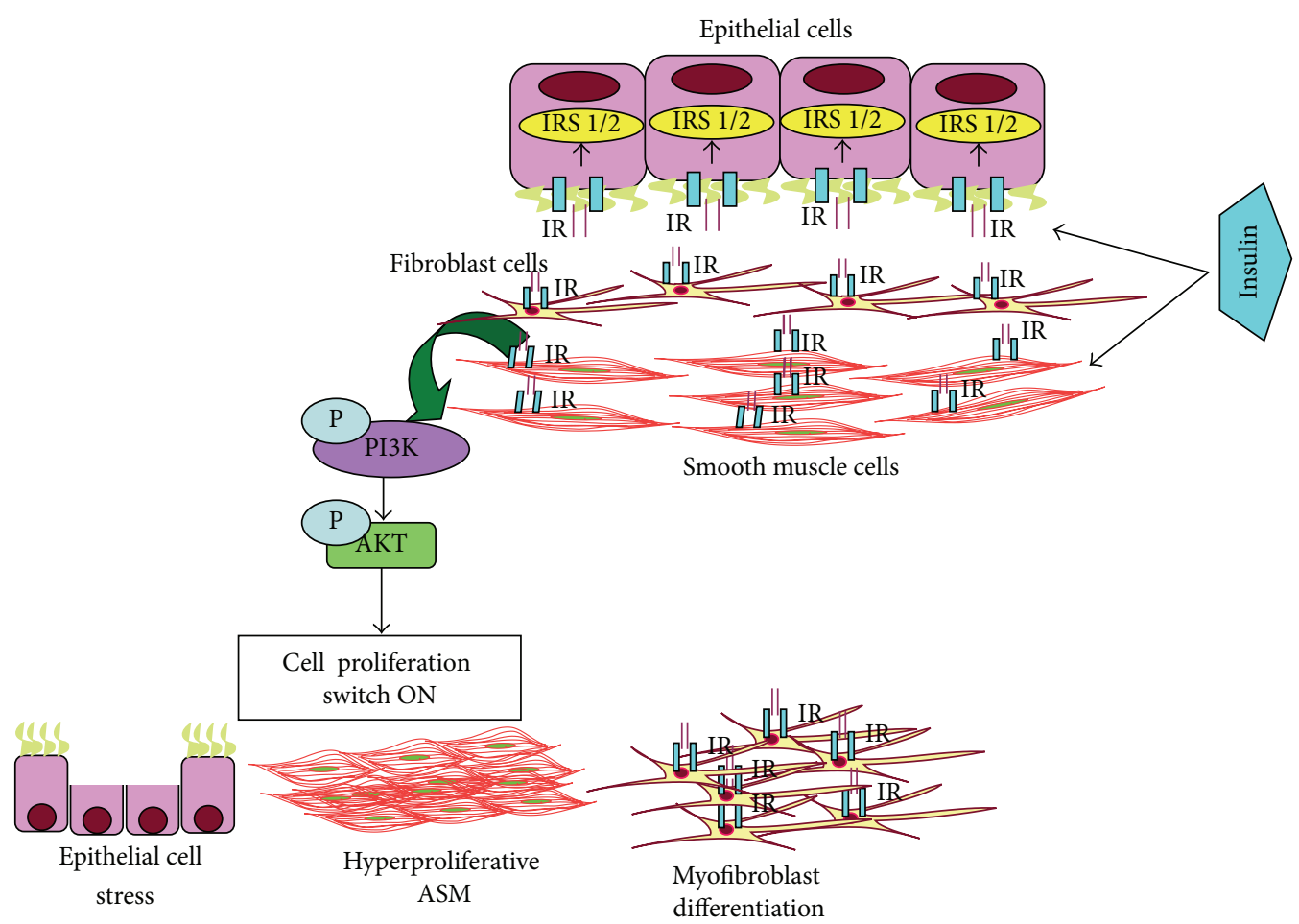

FIgURE 2: A schematic model of how insulin may be involved in regulation of asthma-like changes in lungs.

where fetal hyperinsulinemia in response to maternal hyperglycemia [74-77] results in PI3K/Akt1/mTOR activation and induces RDS [78]. Also, as mentioned previously, high levels of insulin through the PI 3-kinase signaling pathway may also inhibit surfactant protein production expressed in the lung epithelial cells and lung maturation $[37,79,80]$, thus predisposing the immature lung to airway diseases later in life. While these data relate to the developing lung, the relevance of the enhanced PI3/Akt signaling also lies in its well-recognized role in adult asthma. For example, loss of function mutations in the principal inhibitory phosphatases SHIP, PTEN, and INPP4A, are associated with asthma [81], and knockdown of INPP4A induces airway remodeling and hyperresponsiveness. Activation of the PI3/Akt pathway promotes survival of airway epithelial cells as well as ASM and conversely can enhance proliferation [82], thus contributing to airway remodeling. Whether insulin activation of PI3K/Akt is involved in this regard is not currently known. However, insulin has been shown to act via PI3/Akt to inhibit epithelial apoptosis that normally occurs with viral exposure and could thus promote airway remodeling in this context (Figure 2).

\section{Insulin, Wnt $/ \beta$-Catenin Signaling, and Airway Remodeling}

Some studies have also reported insulin regulation of $\mathrm{Wnt} / \beta$ catenin pathway and stimulation of transcription of Lef/Tcfdependent genes via activation of PI3K/Akt and Ras signaling pathways which normally inhibit GSK3- $\beta$ and activate the $\beta$ catenin pathway in hepatocarcinogenesis [83]. Dysregulation of Wnt/ $\beta$-catenin pathway influences many biological processes, including cell fate decisions, stem cell proliferation [84], and axis specification [85-88]. While relationships between insulin and $\mathrm{Wnt} / \beta$-catenin have not been reported in the lung per se, $\mathrm{Wnt} / \beta$-catenin pathways are increasingly recognized as being important in regulation of lung cell proliferation and differentiation [89]. $\beta$-catenin is required for normal lung morphogenesis, and deletion of $\beta$-catenin during critical periods of lung development leads to blocked alveolar epithelial cell differentiation and disruption of alveolar formation [87]. Furthermore, conditional activation of $\beta$ catenin in respiratory epithelial cells leads to altered epithelial cell differentiation by induction of alveolar marker prosurfactant protein $\mathrm{C}$ (SP-C) and causes goblet cell hyperplasia, air space enlargement, and pulmonary tumors. Thus, $\beta$-catenin signaling pathway has a critical role in the differentiation of the respiratory epithelium in the postnatal lung [90]. Accordingly, even during lung development, insulin could potentially promote morphogenesis via activation of the Wnt/ $\beta$-catenin pathway, although it would be important to determine whether the relative timings of insulin versus $\mathrm{Wnt} / \beta$-catenin activation are detrimental or beneficial.

In the adult airway, activated $\beta$-catenin-/TCF-/LEFdependent gene transcription of VEGF [91], matrix proteins such as fibronectin and versican, and proinflammatory enzymes/mediators such as cyclooxygenase (COX)-2 [92] and interleukin (IL-8) suggest the involvement of this pathway in regulation of inflammation and airway remodeling. 
Here too, insulin-mediated activation of $\beta$-catenin signaling could be involved in airway disease pathogenesis. While there is currently no information in the context of asthma per se, data from fibroproliferative lung diseases may be suggestive where activation of $\beta$-catenin signaling is involved [93]. Inhibition of GSK $3 \beta$ and stabilization of $\beta$-catenin is governed by TGF- $\beta$ signaling and leads to altered ECM [94]. Of relevance, diabetes and metabolic syndrome have been associated with increased risk of idiopathic pulmonary fibrosis and COPD $[95,96]$. Whether insulin per se plays a role in these diseases is not known, but if so, modulation of Wnt signaling pathway may be relevant.

Also, in other systems like the heart, Akt-mediated GSK3 $\beta$ phosphorylation leads to increased $\beta$-catenin expression and causes cardiac smooth muscle hypertrophy [97], whether this may be mirrored in the airway smooth muscle, remains to be determined.

\section{Conclusion}

There is substantial data that mechanistically links insulin and insulin like growth factor-1 to lung development and function. It is conceivable but not proven that hyperinsulinemia may lead to development of lung disease, particularly asthma. Experimental studies that directly address this possibility are much needed.

\section{Acknowledgments}

This work was supported by Grants GAP-63 from Lady Tata Memorial Trust and MLP 5502 from the Council of Scientific and Industrial Research (Anurag Agrawal); Fellowship Grant from ICMR (Suchita Singh); and NIH Grants HL088029 and HL056470 (Y. S. Prakash). The authors specially thank Richa Singh and Mahima Sharma for their assistance.

\section{References}

[1] P. Demoly, B. Gueron, K. Annunziata, L. Adamek, and R. D. Walters, "Update on asthma control in five European countries: results of a 2008 survey," European Respiratory Review, vol. 19, no. 116, pp. 150-157, 2010.

[2] A. S. Gershon, C. Wang, J. Guan, and T. To, "Burden of comorbidity in individuals with asthma," Thorax, vol. 65, no. 7, pp. 612-618, 2010.

[3] D. A. Beuther and E. R. Sutherland, "Overweight, obesity, and incident asthma: a meta-analysis of prospective epidemiologic studies," American Journal of Respiratory and Critical Care Medicine, vol. 175, no. 7, pp. 661-666, 2007.

[4] B. H. Thuesen, L. L. N. Husemoen, L.-G. Hersoug, C. Pisinger, and A. Linneberg, "Insulin resistance as a predictor of incident asthma-like symptoms in adults," Clinical and Experimental Allergy, vol. 39, no. 5, pp. 700-707, 2009.

[5] O. O. Adeyeye, A. O. Ogbera, O. O. Ogunleye et al., "Understanding asthma and the metabolic syndrome-a Nigerian report," International Archives of Medicine, vol. 5, no. 1, article 20, 2012.

[6] B. M. Brumpton, C. A. Camargo Jr, P. R. Romundstad, A. Langhammer, Y. Chen, and X. M. Mai, "Metabolic syndrome and incidence of asthma in adults: the HUNT study," European Respiratory Journal, 2013.

[7] J. Park, T. B. Kim, H. Joo, J. S. Lee, S. D. Lee, and Y. M. Oh, "Diseases concomitant with asthma in middle-aged and elderly subjects in Korea: a population-based study," Allergy, Asthma \& Immunology Research, vol. 5, no. 1, pp. 16-25, 2013.

[8] M. Canöz, F. Erdenen, H. Uzun, C. Müderrisoǧlu, and S. Aydin, "The relationship of inflammatory cytokines with asthma and obesity," Clinical and Investigative Medicine, vol. 31, no. 6, pp. E373-E379, 2008.

[9] D. A. Beuther, S. T. Weiss, and E. R. Sutherland, "Obesity and asthma," American Journal of Respiratory and Critical Care Medicine, vol. 174, no. 2, pp. 112-119, 2006.

[10] P. Haldar, I. D. Pavord, D. E. Shaw et al., "Cluster analysis and clinical asthma phenotypes," American Journal of Respiratory and Critical Care Medicine, vol. 178, no. 3, pp. 218-224, 2008.

[11] L. L. N. Husemoen, C. Glümer, C. Lau, C. Pisinger, L. S. Mørch, and A. Linneberg, "Association of obesity and insulin resistance with asthma and aeroallergen sensitization," Allergy, vol. 63, no. 5, pp. 575-582, 2008.

[12] R. A. DeFronzo and E. Ferrannini, "Insulin resistance: a multifaceted syndrome responsible for NIDDM, obesity, hypertension, dyslipidemia, and atherosclerotic cardiovascular disease," Diabetes Care, vol. 14, no. 3, pp. 173-194, 1991.

[13] R. H. Eckel, S. M. Grundy, and P. Z. Zimmet, "The metabolic syndrome," The Lancet, vol. 365, no. 9468, pp. 1415-1428, 2005.

[14] M. Uzunlulu, A. Oguz, C. Gedik, G. Aslan, and S. Arik, "Is prevalence of metabolic syndrome high in patients with asthma?" Acta Clinica Belgica, vol. 66, no. 1, pp. 49-52, 2011.

[15] E. E. Akpinar, S. Akpinar, S. Ertek, E. Sayin, and M. Gulhan, "Systemic inflammation and metabolic syndrome in stable COPD patients," Tüberküloz ve Toraks, vol. 60, no. 3, pp. 230$237,2012$.

[16] J.-P. Després, I. Lemieux, J. Bergeron et al., "Abdominal obesity and the metabolic syndrome: contribution to global cardiometabolic risk," Arteriosclerosis, Thrombosis, and Vascular Biology, vol. 28, no. 6, pp. 1039-1049, 2008.

[17] A. Agrawal, U. Mabalirajan, T. Ahmad, and B. Ghosh, "Emerging interface between metabolic syndrome and asthma," American Journal of Respiratory Cell and Molecular Biology, vol. 44, no. 3, pp. 270-275, 2011.

[18] P. Sonksen and J. Sonksen, "Insulin: understanding its action in health and disease," British Journal of Anaesthesia, vol. 85, no. 1, pp. 69-79, 2000.

[19] E. J. Gallagher and D. LeRoith, "Minireview: IGF, insulin, and cancer," Endocrinology, vol. 152, no. 7, pp. 2546-2551, 2011.

[20] L. Rosenfeld, "Insulin: discovery and controversy," Clinical Chemistry, vol. 48, no. 12, pp. 2270-2288, 2002.

[21] R. Aikawa, M. Nawano, Y. Gu et al., "Insulin prevents cardiomyocytes from oxidative stress-induced apoptosis through activation of PI3 Kinase/Akt," Circulation, vol. 102, no. 23, pp. 2873-2879, 2000.

[22] R. J. Barth, "Insulin resistance, obesity and the metabolic syndrome," South Dakota Medicine, no. 22-27, 2011.

[23] M. Wozniak, B. Rydzewski, S. P. Baker, and M. K. Raizada, "The cellular and physiological actions of insulin in the central nervous system," Neurochemistry International, vol. 22, no. 1, pp. 1-10, 1993.

[24] E. Bugianesi, S. Moscatiello, M. F. Ciaravella, and G. Marchesini, "Insulin resistance in nonalcoholic fatty liver disease," Current Pharmaceutical Design, vol. 16, no. 17, pp. 1941-1951, 2010. 
[25] S. M. Grundy, "Obesity, metabolic syndrome, and cardiovascular disease," Journal of Clinical Endocrinology and Metabolism, vol. 89, no. 6, pp. 2595-2600, 2004.

[26] E. Ferrannini, A. Natali, B. Capaldo, M. Lehtovirta, S. Jacob, and H. Yki-Järvinen, "Insulin resistance, hyperinsulinemia, and blood pressure: role of age and obesity. European Group for the Study of Insulin Resistance (EGIR)," Hypertension, vol. 30, no. 5, pp. 1144-1149, 1997.

[27] M. Hamed, P. Metcalf, and J. Kolbe, "Fixed airflow obstruction among nonsmokers with asthma: a case-comparison study," Journal of Asthma, vol. 50, no. 6, pp. 606-612, 2013.

[28] R. Kaaks, "Nutrition, hormones, and breast cancer: is insulin the missing link?" Cancer Causes and Control, vol. 7, no. 6, pp. 605-625, 1996.

[29] R. Kaaks, A. Lukanova, and M. S. Kurzer, "Obesity, endogenous hormones, and endometrial cancer risk: a synthetic review," Cancer Epidemiology Biomarkers and Prevention, vol. 11, no. 12, pp. 1531-1543, 2002.

[30] E. T. Petridou, T. N. Sergentanis, C. N. Antonopoulos et al., "Insulin resistance: an independent risk factor for lung cancer?" Metabolism: Clinical and Experimental, vol. 60, no. 8, pp. 11001106, 2011.

[31] V. T. Samuel, K. F. Petersen, and G. I. Shulman, "Lipid-induced insulin resistance: unravelling the mechanism," The Lancet, vol. 375, no. 9733, pp. 2267-2277, 2010.

[32] N. A. Tritos and C. S. Mantzoros, "Clinical review 97: syndromes of severe insulin resistance," Journal of Clinical Endocrinology and Metabolism, vol. 83, no. 9, pp. 3025-3030, 1998.

[33] R. E. Ulane, J. E. Graeber, and R. Steinherz, "A comparison of insulin receptors in the developing fetal lung in normal and in streptozotocin-induced diabetic pregnancies," Pediatric Pulmonology, vol. 1, no. 3, supplement, pp. S86-S90, 1985.

[34] W. K. Morishige, C. A. Uetake, F. C. Greenwood, and J. Akaka, "Pulmonary insulin responsivity: in vivo effects of insulin on the diabetic rat lung and specific insulin binding to lung receptors in normal rats," Endocrinology, vol. 100, no. 6, pp. 1710-1722, 1977.

[35] N. D. Neufeld, L. M. Corbo, and S. A. Kaplan, "Plasma membrane insulin receptors in fetal rabbit lung," Pediatric Research, vol. 15, no. 7, pp. 1058-1062, 1981.

[36] F. R. Sodoyez-Goffaux, J. C. Sodoyez, and C. J. de Vos, "Insulin receptors in the fetal rat lung. A transient characteristic of fetal cells?" Pediatric Research, vol. 15, no. 9, pp. 1303-1307, 1981.

[37] O. L. Miakotina, K. L. Goss, and J. M. Snyder, "Insulin utilizes the PI 3-kinase pathway to inhibit SP-A gene expression in lung epithelial cells," Respiratory Research, vol. 3, article 27, 2002.

[38] S. A. Dekowski and J. M. Snyder, "Insulin regulation of messenger ribonucleic acid for the surfactant-associated proteins in human fetal lung in vitro," Endocrinology, vol. 131, no. 2, pp. 669-676, 1992.

[39] M. B. Azad, A. B. Becker, and A. L. Kozyrskyj, "Association of maternal diabetes and child asthma," Pediatric Pulmonology, vol. 48, no. 6, pp. 545-552, 2013.

[40] N. Vrachnis, N. Antonakopoulos, Z. Iliodromiti et al., "Impact of maternal diabetes on epigenetic modifications leading to diseases in the offspring," Journal of Diabetes Research, vol. 2012, Article ID 538474, 6 pages, 2012.

[41] H. Ikeda, I. Shiojima, T. Oka et al., "Increased Akt-mTOR signaling in lung epithelium is associated with respiratory distress syndrome in mice," Molecular and Cellular Biology, vol. 31, no. 5, pp. 1054-1065, 2011.
[42] M. Hallman, D. Wermer, B. L. Epstein, and L. Gluck, "Effects of maternal insulin or glucose infusion on the fetus: Study on lung surfactant phospholipids, plasma myoinositol, and fetal growth in the rabbit," American Journal of Obstetrics and Gynecology, vol. 142, no. 7, pp. 877-882, 1982.

[43] R. U. Agu, M. I. Ugwoke, M. Armand, R. Kinget, and N. Verbeke, "The lung as a route for systemic delivery of therapeutic proteins and peptides," Respiratory Research, vol. 2, no. 4, pp. 198-209, 2001.

[44] F.-Y. Liu, D. O. Kildsig, and A. K. Mitra, "Pulmonary biotransformation of insulin in rat and rabbit," Life Sciences, vol. 51, no. 21, pp. 1683-1689, 1992.

[45] Z. Shen, Q. Zhang, S. Wei, and T. Nagai, "Proteolytic enzymes as a limitation for pulmonary absorption of insulin: in vitro and in vivo investigations," International Journal of Pharmaceutics, vol. 192, no. 2, pp. 115-121, 1999.

[46] L. Ceglia, J. Lau, and A. G. Pittas, "Meta-analysis: efficacy and safety of inhaled insulin therapy in adults with diabetes mellitus," Annals of Internal Medicine, vol. 145, no. 9, pp. 665675, 2006.

[47] G. T. McMahon and R. A. Arky, "Inhaled insulin for diabetes mellitus," The New England Journal of Medicine, vol. 356, no. 5, pp. 497-502, 2007.

[48] A. Viardot, S. T. Grey, F. Mackay, and D. Chisholm, "Potential antiinflammatory role of insulin via the preferential polarization of effector T cells toward a T helper 2 phenotype," Endocrinology, vol. 148, no. 1, pp. 346-353, 2007.

[49] E. Lessmann, G. Grochowy, L. Weingarten et al., "Insulin and insulin-like growth factor-1 promote mast cell survival via activation of the phosphatidylinositol-3-kinase pathway," Experimental Hematology, vol. 34, no. 11, pp. 1532-1541, 2006.

[50] C. A. Lasagna-Reeves, A. L. Clos, T. Midoro-Hiriuti, R. M. Goldblum, G. R. Jackson, and R. Kayed, "Inhaled insulin forms toxic pulmonary amyloid aggregates," Endocrinology, vol. 151, no. 10, pp. 4717-4724, 2010.

[51] L. M. Hunt, M. A. Valenzuela, and J. A. Pugh, "NIDDM patients' fears and hopes about insulin therapy: the basis of patient reluctance," Diabetes Care, vol. 20, no. 3, pp. 292-298, 1997.

[52] J. Lenzer, "Inhaled insulin is approved in Europe and United States," British Medical Journal, vol. 332, no. 7537, article 321, 2006.

[53] H. Shapiro, I. Kagan, M. Shalita-Chesner, J. Singer, and P. Singer, "Inhaled aerosolized insulin: a "topical" anti-inflammatory treatment for acute lung injury and respiratory distress syndrome?" Inflammation, vol. 33, no. 5, pp. 315-319, 2010.

[54] H. K. Kim, C. H. Lee, J. M. Kim, O. Ayush, S. Y. Im, and H. K. Lee, "Biphasic late airway hyperresponsiveness in a murine model of asthma," International Archives of Allergy and Immunology, vol. 160, no. 2, pp. 173-183, 2013.

[55] S. Zuyderduyn, M. B. Sukkar, A. Fust, S. Dhaliwal, and J. K. Burgess, "Treating asthma means treating airway smooth muscle cells," European Respiratory Journal, vol. 32, no. 2, pp. 265-274, 2008.

[56] P. Cohen, J. P. Noveral, A. Bhala, S. E. Nunn, D. J. Herrick, and M. M. Grunstein, "Leukotriene D4 facilitates airway smooth muscle cell proliferation via modulation of the IGF axis," American Journal of Physiology: Lung Cellular and Molecular Physiology, vol. 269, no. 2, part 1, pp. L151-L157, 1995.

[57] J. P. Noveral, A. Bhala, R. L. Hintz, M. M. Grunstein, and P. Cohen, "Insulin-like growth factor axis in airway smooth muscle cells," American Journal of Physiology, vol. 267, no. 6, part 1, pp. L761-L765, 1994. 
[58] M. D. Kelleher, M. K. Abe, T.-S. O. Chao et al., "Role of MAP kinase activation in bovine tracheal smooth muscle mitogenesis," American Journal of Physiology: Lung Cellular and Molecular Physiology, vol. 268, no. 6, part 1, pp. L894-L901, 1995.

[59] T. L. Ediger and M. L. Toews, "Synergistic stimulation of airway smooth muscle cell mitogenesis," Journal of Pharmacology and Experimental Therapeutics, vol. 294, no. 3, pp. 1076-1082, 2000.

[60] R. Gosens, S. A. Nelemans, M. Hiemstra, M. M. Grootte Bromhaar, H. Meurs, and J. Zaagsma, "Insulin induces a hypercontractile airway smooth muscle phenotype," European Journal of Pharmacology, vol. 481, no. 1, pp. 125-131, 2003.

[61] J. A. Hirota, T. T. B. Nguyen, D. Schaafsma, P. Sharma, and T. Tran, "Airway smooth muscle in asthma: phenotype plasticity and function," Pulmonary Pharmacology and Therapeutics, vol. 22, no. 5, pp. 370-378, 2009.

[62] R. Gosens, D. Schaafsma, H. Meurs, J. Zaagsma, and S. A. Nelemans, "Role of Rho-kinase in maintaining airway smooth muscle contractile phenotype," European Journal of Pharmacology, vol. 483, no. 1, pp. 71-78, 2004.

[63] M. Papagianni, A. Hatziefthimiou, G. Chachami, K. Gourgoulianis, P.-A. Molyvdas, and E. Paraskeva, "Insulin causes a transient induction of proliferation via activation of the PI3kinase pathway in airway smooth muscle cells," Experimental and Clinical Endocrinology and Diabetes, vol. 115, no. 2, pp. 118123, 2007.

[64] D. Schaafsma, K. D. McNeill, G. L. Stelmack et al., "Insulin increases the expression of contractile phenotypic markers in airway smooth muscle," American Journal of Physiology: Cell Physiology, vol. 293, no. 1, pp. C429-C439, 2007.

[65] B. G. J. Dekkers, D. Schaafsma, T. Tran, J. Zaagsma, and H. Meurs, "Insulin-induced laminin expression promotes a hypercontractile airway smooth muscle phenotype," American Journal of Respiratory Cell and Molecular Biology, vol. 41, no. 4, pp. 494-504, 2009.

[66] M. Patarroyo, K. Tryggvason, and I. Virtanen, "Laminin isoforms in tumor invasion, angiogenesis and metastasis," Seminars in Cancer Biology, vol. 12, no. 3, pp. 197-207, 2002.

[67] D. Schaafsma, R. Gosens, J. M. Ris, J. Zaagsma, H. Meurs, and S. A. Nelemans, "Insulin induces airway smooth muscle contraction," British Journal of Pharmacology, vol. 150, no. 2, pp. 136-142, 2007.

[68] K. D. Courtney, R. B. Corcoran, and J. A. Engelman, “The PI3K pathway as drug target in human cancer," Journal of Clinical Oncology, vol. 28, no. 6, pp. 1075-1083, 2010.

[69] J. A. Engelman, J. Luo, and L. C. Cantley, "The evolution of phosphatidylinositol 3-kinases as regulators of growth and metabolism," Nature Reviews Genetics, vol. 7, no. 8, pp. 606-619, 2006.

[70] S. Uddin, A. R. Hussain, A. K. Siraj et al., "Role of phosphatidylinositol $3^{\prime}$-kinase/AKT pathway in diffuse large B-cell lymphoma survival," Blood, vol. 108, no. 13, pp. 4178-4186, 2006.

[71] S. Jia, Z. Liu, S. Zhang et al., "Essential roles of PI(3)K-p110 $\beta$ in cell growth, metabolism and tumorigenesis," Nature, vol. 454, no. 7205, pp. 776-779, 2008.

[72] Z. A. Knight, B. Gonzalez, M. E. Feldman et al., "A pharmacological map of the PI3-K family defines a role for p110 $\alpha$ in insulin signaling," Cell, vol. 125, no. 4, pp. 733-747, 2006.

[73] T. Numata, J. Araya, S. Fujii et al., "Insulin-dependent phosphatidylinositol 3-kinase/Akt and ERK signaling pathways inhibit TLR3-mediated human bronchial epithelial cell apoptosis," Journal of Immunology, vol. 187, no. 1, pp. 510-519, 2011.
[74] T. D. Clausen, E. Mathiesen, P. Ekbom, E. Hellmuth, T. Mandrup-Poulsen, and P. Damm, "Poor pregnancy outcome in women with type 2 diabetes," Diabetes Care, vol. 28, no. 2, pp. 323-328, 2005.

[75] C. A. Crowther, J. E. Hiller, J. R. Moss, A. J. McPhee, W. S. Jeffries, and J. S. Robinson, "Effect of treatment of gestational diabetes mellitus on pregnancy outcomes," The New England Journal of Medicine, vol. 352, no. 24, pp. 2477-2486, 2005.

[76] D. M. Jensen, P. Damm, L. Moelsted-Pedersen et al., “Outcomes in type 1 diabetic pregnancies: a nationwide, population-based study," Diabetes Care, vol. 27, no. 12, pp. 2819-2823, 2004.

[77] J. L. Nold and M. K. Georgieff, "Infants of diabetic mothers," Pediatric Clinics of North America, vol. 51, no. 3, pp. 619-637, 2004.

[78] V. Compernolle, K. Brusselmans, T. Acker et al., "Loss of HIF- $2 \alpha$ and inhibition of VEGF impair fetal lung maturation, whereas treatment with VEGF prevents fatal respiratory distress in premature mice," Nature Medicine, vol. 8, no. 7, pp. 702-710, 2002.

[79] M. F. Robert, R. K. Neff, and J. P. Hubbell, "Association between maternal diabetes and the respiratory distress syndrome in the newborn," The New England Journal of Medicine, vol. 294, no. 7, pp. 357-360, 1976.

[80] E. Zmora, I. H. Gewolb, and D. L. Shapiro, "Effects of insulin and glucose on pulmonary insulin receptors in late gestation fetal rats," Experimental Lung Research, vol. 18, no. 2, pp. 247-258, 1992.

[81] J. Aich, U. Mabalirajan, T. Ahmad, A. Agrawal, and B. Ghosh, "Loss-of-function of inositol polyphosphate-4-phosphatase reversibly increases the severity of allergic airway inflammation," Nature Communications, vol. 3, article 877, 2012.

[82] S. J. Hirst, J. G. Martin, J. V. Bonacci et al., "Proliferative aspects of airway smooth muscle," Journal of Allergy and Clinical Immunology, vol. 114, no. 2, supplement, pp. S2-S17, 2004.

[83] C. Desbois-Mouthon, A. Cadoret, M.-J. Blivet-Van Eggelpoël et al., "Insulin and IGF-1 stimulate the $\beta$-catenin pathway through two signalling cascades involving GSK-3 $\beta$ inhibition and Ras activation," Oncogene, vol. 20, no. 2, pp. 252-259, 2001.

[84] Y. Teng, X. Wang, Y. Wang, and D. Ma, "Wnt/ $\beta$-catenin signaling regulates cancer stem cells in lung cancer A549 cells," Biochemical and Biophysical Research Communications, vol. 392, no. 3, pp. 373-379, 2010.

[85] S. R. Jansen, A. M. Van Ziel, H. A. Baarsma, and R. Gosens, “ $\beta$ catenin regulates airway smooth muscle contraction," American Journal of Physiology: Lung Cellular and Molecular Physiology, vol. 299, no. 2, pp. L204-L214, 2010.

[86] J. R. Miller and R. T. Moon, "Analysis of the signaling activities of localization mutants of $\beta$ - catenin during axis specification in Xenopus," Journal of Cell Biology, vol. 139, no. 1, pp. 229-243, 1997.

[87] M. L. Mucenski, S. E. Wert, J. M. Nation et al., “ $\beta$-catenin is required for specification of proximal/distal cell fate during lung morphogenesis," Journal of Biological Chemistry, vol. 278, no. 41, pp. 40231-40238, 2003.

[88] A. Wodarz and R. Nusse, "Mechanisms of Wnt signaling in development," Annual Review of Cell and Developmental Biology, vol. 14, pp. 59-88, 1998.

[89] W. J. Nelson and R. Nusse, "Convergence of Wnt, $\beta$-catenin, and cadherin pathways," Science, vol. 303, no. 5663, pp. 1483-1487, 2004 . 
[90] M. L. Mucenski, J. M. Nation, A. R. Thitoff et al., “ $\beta$-catenin regulates differentiation of respiratory epithelial cells in vivo," American Journal of Physiology: Lung Cellular and Molecular Physiology, vol. 289, no. 6, pp. L971-L979, 2005.

[91] X. Zhang, J. P. Gaspard, and D. C. Chung, "Regulation of vascular endothelial growth factor by the Wnt and K-ras pathways in colonic neoplasia," Cancer Research, vol. 61, no. 16, pp. 6050-6054, 2001.

[92] S. S. Barbieri and B. B. Weksler, "Tobacco smoke cooperates with interleukin- $1 \beta$ to alter $\beta$-catenin trafficking in vascular endothelium resulting in increased permeability and induction of cyclooxygenase-2 expression in vitro and in vivo," FASEB Journal, vol. 21, no. 8, pp. 1831-1843, 2007.

[93] E. Bowley, D. B. O’Gorman, and B. S. Gan, “ $\beta$-catenin signaling in fibroproliferative disease," Journal of Surgical Research, vol. 138, no. 1, pp. 141-150, 2007.

[94] R. Gosens, H. Meurs, and M. Schmidt, “The GSK-3/ $\beta$-cateninsignalling axis in smooth muscle and its relationship with remodelling," Naunyn-Schmiedeberg's Archives of Pharmacology, vol. 378, no. 2, pp. 185-191, 2008.

[95] T. Enomoto, J. Usuki, A. Azuma, T. Nakagawa, and S. Kudoh, "Diabetes mellitus may increase risk for idiopathic pulmonary fibrosis," Chest, vol. 123, no. 6, pp. 2007-2011, 2003.

[96] N. Leone, D. Courbon, F. Thomas et al., "Lung function impairment and metabolic syndrome the critical role of abdominal obesity," American Journal of Respiratory and Critical Care Medicine, vol. 179, no. 6, pp. 509-516, 2009.

[97] S. Haq, A. Michael, M. Andreucci et al., "Stabilization of $\beta$ catenin by a Wnt-independent mechanism regulates cardiomyocyte growth," Proceedings of the National Academy of Sciences of the United States of America, vol. 100, no. 8, pp. 4610-4615, 2003. 


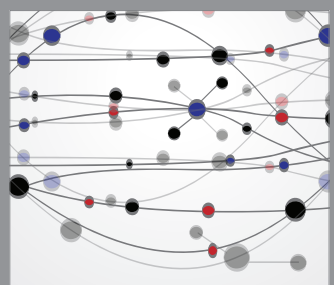

The Scientific World Journal
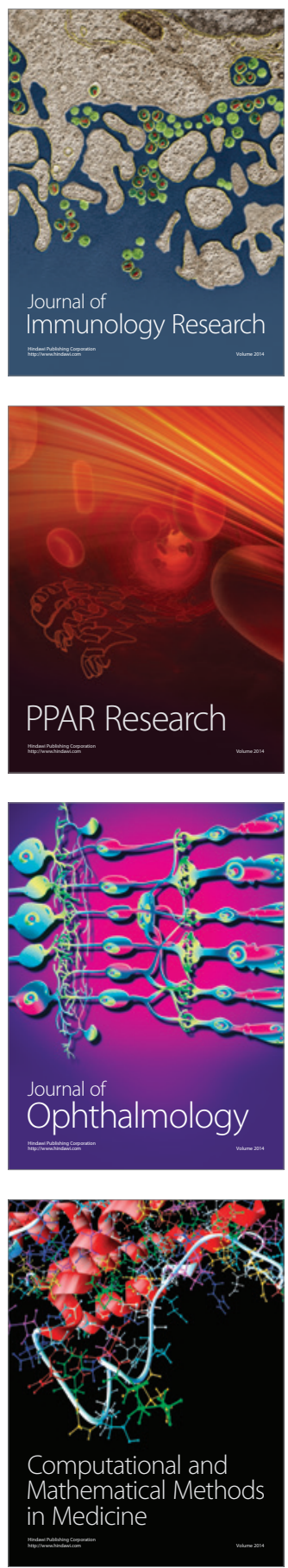

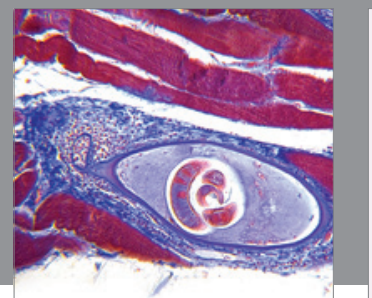

Gastroenterology

Research and Practice
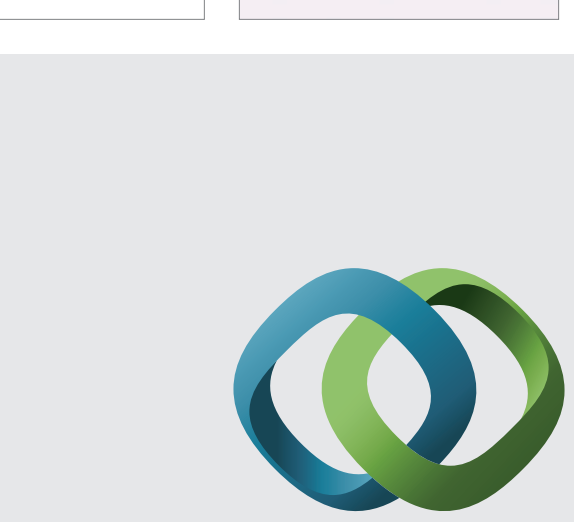

\section{Hindawi}

Submit your manuscripts at

http://www.hindawi.com
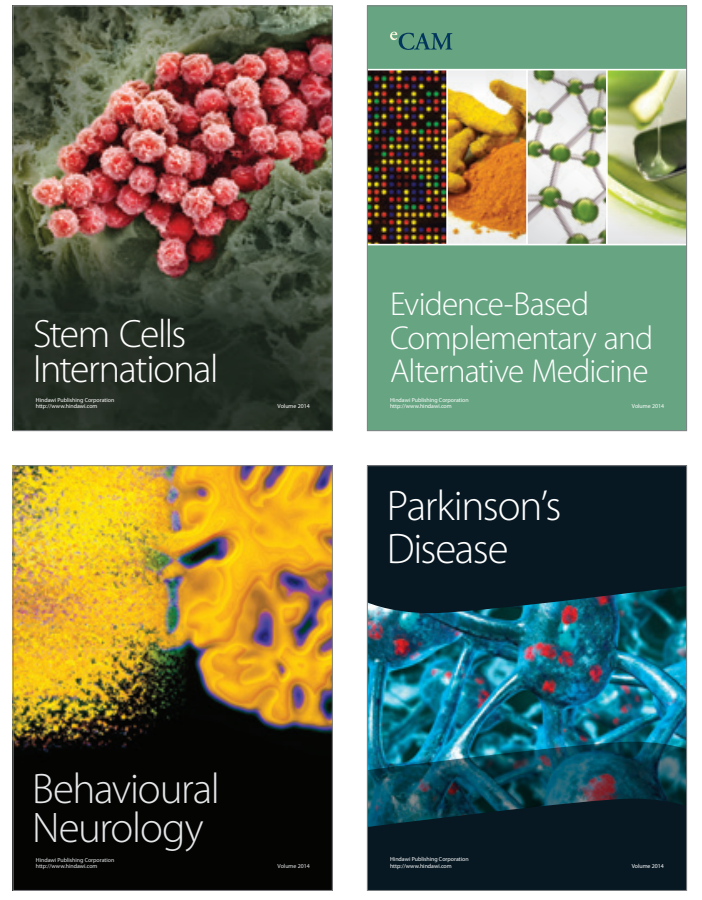
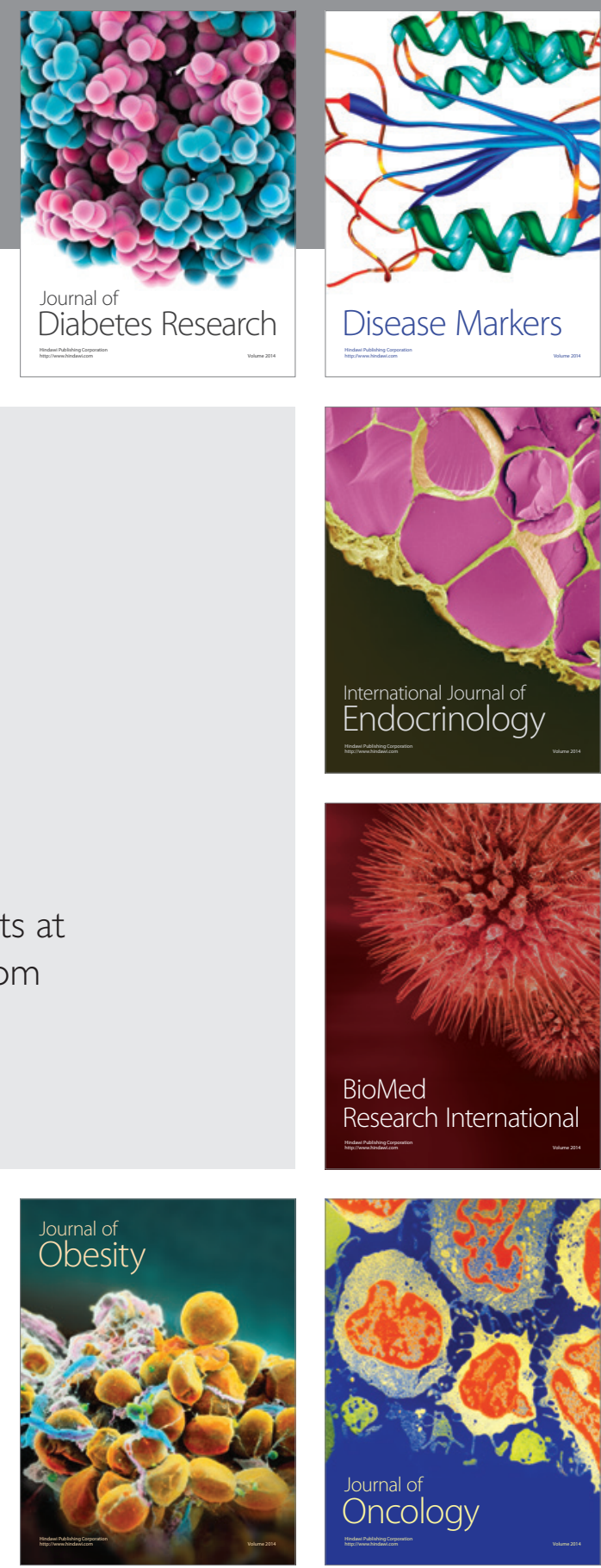

Disease Markers
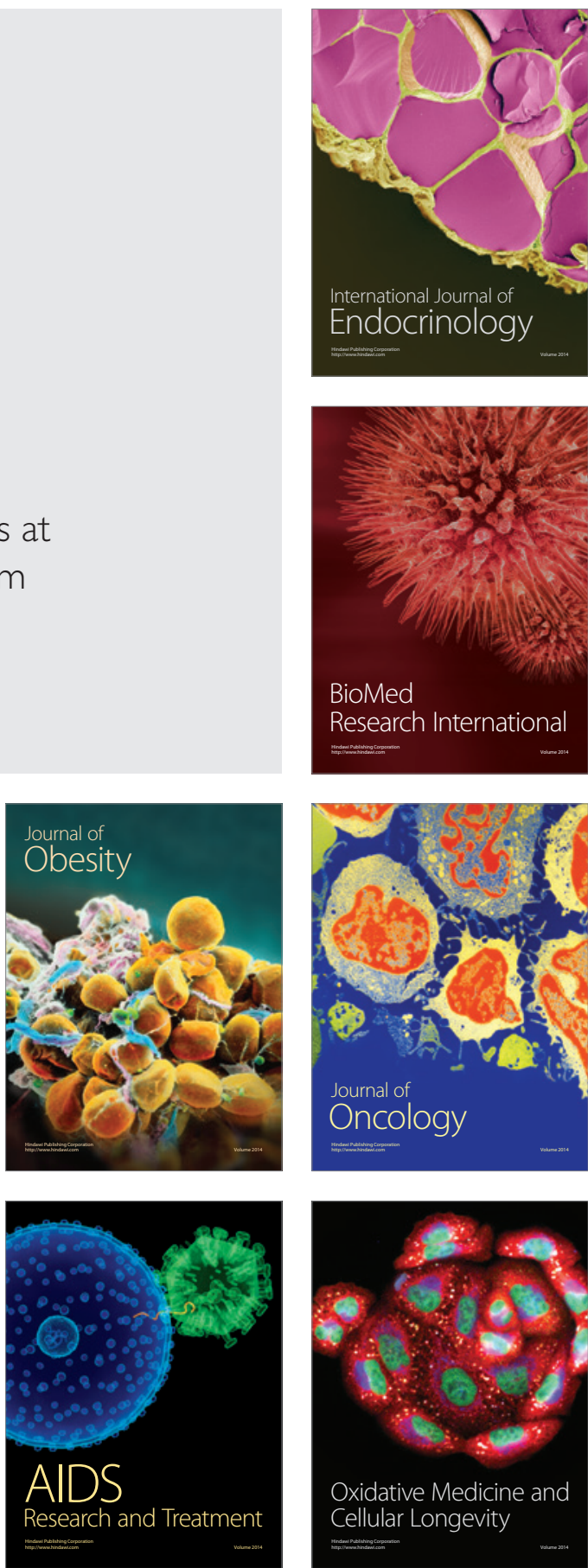